\title{
CULTURA Y CIENCIA DEL DERECHO
}

\begin{abstract}
Sumarjo: 1. Culluta y técnicas cientificas. z. Métodó cièntifico y finalidades culturales. El problema de la naturaleza de los conceptos juridicos. 3 . Las elecciones metodológicas del jurista y la teoria general del derecho. 4. Juicio de hecho y elemento talorador. en el análisis del lenguaje juridico. Imposibilidad de la ciencia juridica como conoci. miento puramente empirico y descriptivo. 5. El recurso a los hechos y las premisas valorativas ${ }^{\dagger}$ de las hipótesis metodológicas del jurista. La función de la filosofia en relación con la teoria general del derecho.
\end{abstract}

1. Una de las funciones fundamentales y quizás incluso la razón de ser de la filosofía del derecho, es poner en claro las relaciones que existen entre la "cultura" y cualquiera especie de actividad que pueda clasificarse como jurídica (según los significados de uso de las palabras "derecho", "jurídico", etcétera).

La palabra "cultura" puede ser útilmente usada para indicar el conjunto de las finalidades fundamentales, de los intereses básicos, de los llamados valores prácticos, teóricos, estéticos, ,religiosos, etc., que caracterizan determinado ambiente social en cierto periodo o momento histórico. ${ }^{{ }^{*}}$ A su vez, los llamados valores, los fines fundamentales y los intereses básicos son aquí entendidos como fines últimos, esto es, como finalidades que, precisamente en cúanto son pensadas como últimas, no pueden ser contemporáneamente concebidas como medios para la realización de fines ulteriores. En este sentido la serie de los fines últimos, o de los valores o de los intereses fundamentales, es lo que constituye, en determinada situación histórica, ambiental y social, el límite que circunscribe las posibilidades de elección y de acción que se ofrecen a los individuos insertos en esa situación. 2 ¿Cuáles son; por

1 Para referencias bibliográficas remito, a $\mathrm{mi}$ ensayo "Valutazioni morali e giuridiche nella crisi dell'etica individuale", in Studi Senesi, 1950, v. LXII, p. 235 y siguientes. Sobre la problematicidad y sobre los límites de la noción de cultura; desde el ppunto de vista de E. Husserl, ver E. Fink. "Welt und Geschichte", en Actes du deuxième Colloque International de Phénoménologie, Den Haag, 1959 , págs. 146-147. Entre las obras más recientes, ver, de L. Recasénš Siches, Tratado General de Filosofia del Derecho, México, 1959, especialmente las págs. 114 y siguientes; de L. Cabral.De Moncada, Da Essencia e Conceito do Politico, Coimbra, 1961 , especialmente págs. 11 y siguientes. - Es particularmente impórtante, en relación con el argumento que aquí interesa; el reciente ensayo de Palazolo: "Sul problema della cultura", cn. Studi in memoria di L. Mossa, 1961, págs. 3-14 del extracto anticipado.

2 Para una perspectiva de las relaciońes entre los significados de la palabra "valor" y èl significado de la palabra "fin", y sobre la irreductibilidad del discurso axiológico a los'términos de una pura y simple perspectiva teleologica, remíto a las agudas observaciones de M. Reale en el prefacio a mi estudio Moral e Direito na Doutrina da Simpatia, São Paulo, 1952, págs. 9 y siguientes, donde, entre otras cosas, en la pág. 14, Reale dice: "Se todo valor tende a realizar-se, todo valor se abre como possibilidade de fins. Todo valor pode ser reconhecido como fim, sendo fim ético apenás aquêle che surge do réconbecimento racional de um valor como algo que nâo pode deixar de ser um motivo necessário 
ejemplo, según los casos y en igualdad de ciertas condiciones, las posibilidades de acción que hoy se ofrecen a un individuo que vive en la llamada sociedad comunista frente a otro que vive en la llamada sociedad capitalista? Evidentemente esta pregunta, incluso si necesariamente es planteada en términos abstractos y esquemáticos, coincide más o menos con las siguientes: ¿Cuáles son las finalidades últimas, los intereses fundamentales y los valores que caracterizan el ambiente cultural comunista frente al capitalista? ¿Cuál es, por ejemplo, la diferencia entre el ambiente cultural de una región de la América del Sur y otra del Norte de Italia, es decir, qué posibilidades de acción —según las diversas actividades posibles- se abren respectivamente a los individuos que pertenecen a esos diversos ambientes culturales?)

El límite que circunscribe las posibilidades de elección y de acción que se ofrecen a los individuos de la situación cultural a que pertenecen, es sin duda históricamente mudable. Por una parte, tal límite condiciona las acciones de los individuos e influye sobre ellas, mientras que, por otra, se encuentra condicionado y modificado por éstas de modo más o menos intenso, según los casos. Bajo este aspecto la cultura puede ser entendida, sin más, como conciencia que el individuo tiene de la situación ambiental y social en que vive; de los límites que la realidad ambiental ofrece a su acción y de las posibilidades que su acción tiene de modificar dicha realidad. No existe una conciencia individual desconectada, por decirlo así, de la situación ambiental en que el individuo vive; ni existe, a la inversa, una situación ambiental que pueda ser concebida como totalmente desconectada de la conciencia que el individuo tiene de si mismo y de sus posibilidades de pensamiento y de acción, o como exterior a tal conciencia. ${ }^{3}$

Entendida así, como conjunto de los valores y de los fines últimos que se ofrecen al hombre en el ambiente social en que vive, la cultura es también, en consecuencia, el horizonte que circunscribe las posibilidades que se abren a la actividad técnica. Los desarrollos de la técnica contemporánea presuponen la situación cultural ${ }^{4}$ del hombre contemporáneo y están con-

e indeclinável da açăo. Quando o valor se insere no plano da conduta e faz-se conduta dando, ao homen $\mathrm{e}$ às coisas, um significado essencial no todo do viver coletivo, temos o fim ético, que é acompanhado sempre de um reconhecimento de objetitridade, visto trans. cender sempre a mera escolha empirica".

3 Sobre la noción de "conciencia práctica" ver las agudas observaciones de A. Falchi en el reciente ensayo "Socialita dell'azione e coscienza pratica", en el volumen colectivo Scritti vari di filosofia del diritto, raccolti per l'inaugurazione della Biblioteca Giargio Del Vecchio, Mìlàn, 1961, especialmente las págs. $167 \mathrm{y}$ siguientes.

4 La palabra "civilización" es usada más bien por algunos autores para designar un complejo de actividades bajo el aspecto técnico, mientras que el vocablo "cultura" hace referencia a actividades de artistas, poetas, literatos, etc. Ver, por ejemplo, Donoso Cortés, Antecedentes sobre la Cuestión de Oriente, en Obras Completas, T. I, Madrid, 1944, pág. $59^{6 .}$

El pensamiento poético, por ejemplo, tiene, según algunos escritores, una función propia de descubrimiento y anticipación de los mismos campos y horizontes culturales en cuyo ámbito los desarrollos de las técnicas y de las civilizaciones encuentran el espacio y 
-dicionados por ella. Por otra parte, esa situación no puede no hallarse continuamente influida ni dejar de ser modificada por los desarrollos de la técnica. 'La técnica como elección, como organización y como uso de los medios idóneos para la realización de fines, no puede no incidir sobre las finalidades últimas que caracterizan el horizonte que circunscribe la situación củltural del hombre contemporáneo. La elección y el uso de los medios puede producir el efecto de modificar los fines. Cultura y técnica se encuentran intrínsecamente conectadas entre sí en una relación histórica de distinción, de polaridad y de recíproca implicación. En el ámbito de esta relación concreta la cultura es siempre, como elemento irreductible e ineliminäble, el horizonte móvil que circunscribe las posibilidades y los fines últimos que a la áctividad técnica se ofrecen.

El significado y la elección de un fin último no es, repito, exclusivamente expresable en los términos de una rélación de -medio a fin, precisamente por el hecho de que, cuando se habla de un fin que ha sido postulado o concebido como último, se alude a un fin que no puede ser postulado ni concebido a su vez como medio o, en otras palabràs, que no puede funcionar nuevamente en forma medial para la realización de un fin ulterior. Por esto la elección y la determinación de un fin último entre varios fines últimos posibles, no siendo exclusivamente reducible a los términos de una relación de medio a fin, no es, en sentido estricto, cientificamente expresable, no puede controlarse con métodos de verificación analítica o experimental y no es previsible. Solamente pueden ser controlados $y$, en cierto sentido, previstos los medios idóneos para la realización de un fin último, pero no puede sér científicamente expresada y controlada la elección y la determinación de un fin último entre varios fines últimos posibles. 5

las condiciones de su actuación. En este sentido, verbigracia, se ha podido decir justa. mente de Hölderlin: “.... die. $\therefore$ herrliche Schönheit seiner Dichtung ist nicht'. allein der Grund. Vielmehr offenbart sich durch sein Werk und durch seine Gestalt das Wesen der Dichtung selbst, die-ñicht etwa Spiel und Ornament, sondern tiefes Eiñdringen in dic Struktur dor Welt ist" (P." Bertaux, en F. Hölderlin, Dichtung, Schriften, Briefe, Francfort del Meno, Hamburgo, 1957, Vorwort, págs. $7-24)$. Ver además, sobre la historia de un moderno planteamiento, el sugestivo capítulo "Das philosophische Problem der Kunst" en -el libro de ,L. Landgrebe Philosophie der Gegenwart, Bonn; 1952, págs. 117-136. Asimismo, el importante planteamiento de V: Ferreira da Silva, Exegese da Ação, Sáo Paulo, págs. 45 y siguientes.

* Contra el dogmatismo extremo de ciertas posiciones racionalistas desce cuyo ángulo visual los fines últimos son considerados eternamente idénticos a sí mismos, universales e inmutables - al menos formalmente- y contra el dogmatismo opuesto de ciertos neopositivistas y nèoempiristas, para quienes la elección de un fin último es absolutamente arbitraria y carece de significado, y contrá la afirmación que (extramuros del llamado 'neopositivismo)' hace, por ejemplo, Kelsen, de que el planteamiento de un último fin de justicia corresponde a un ideal irracional; contra todos estos dogmatismos, entre sí opuestos, la elección de un fín último no cs, en mi sentir, exactamente califićablè ni como absolútamente racional, ni como absolutamente irracional. Justamente decía Dewey (Theory of Väluation, Chicago, 1939, pág. 35) que las elecciones de los fines implican siempre la 
Sólo en un mundo en que no hubiese nada nuevo, en donde todo fuese previsible y cada momento histórico constituyese una repetición del pasado, la elección de los medios podría ser exclusivamente determinante de la elección de los fines, y la cultura vendría a quedar absorbida por la técnica; las posibilidades y las finalidades abiertas a la acción del hombre serían previsibles del todo y controlables de manera específicamente científica. Sin embargo, en este caso, como se ha dicho muy bien, nos encontrariamos frente a una gran paradoja. Al conseguir el hombre el máximo nivel de racionalidad en el dominio de la realidad, se encontraría de pronto privado de ideales y de fines; habiéndose enseñoreado de todos los medios idóneos para la realización de sus tareas, a la postre se encontraría privado de tareas y de fines por elegir y realizar; le faltaría "toda voluntad de dar a la historia un sentido" $y$, por consiguiente, "toda capacidad de comprenderla"."

Para no caer en semejante paradoja, y hacer que adquieran significado proposiciones como éstas: "voluntad de dar sentido a la realidad en que se vive", "capacidad de comprenderla", "realización de las propias tareas", "trazo y realización de nuestro Lebensplan"," es necesario que tenga significado la distinción entre cultura, por un lado, y ciencia y técnica, por el otro, al menos en el ámbito de un nexo concreto y dinámico de recíproca implicación. Cuando se establecé de modo firme el significado de tal distinción, resulta que la filosofía, en cuanto distinta de la ciencia y de la técnica, puede ser considerada y concebida como actividad que sigue, expresa, interpreta y, por tanto, en ciertos casos también, logra anticipar los movimientos de la cultura, o, como se ha dicho, dè las posibilidades y finalidades últimas que cada vez se ofrecen a las acciones y a los comportamientos humanos a través de la mutación de las situaciones históricas. (Incluso cuando los llamados sistemas filosóficos miran hacia las verdades eternas e inmutables, se trata siempre, sin embargo, de esas verdades que se juzgan eternas $\mathrm{e}$ inmutables en el ámbito de los ambientes y de las estructuras culturales de que tales sistemas emergen.)

visión anticipada de las condiciones y de los medios idóneos de realización. Por tal razón, bajo este aspecto, también las elecciones de los fines últimos no son absolutamente irracionales y arbitrarias. Pero, por otra parte, no se trata siquiera, en mi opinión, de elecciones absolutamente racionales, que sean científicamente (empírica y analíticamente) previsibles y controlables del todo, ya que prccisamente se trata de elecciones de fines que son, cada vez, postulados como últimos y, en cuanto tales, como no susceptibles de funcionar como medios, relativamente a finalidades ulteriores. (Sobre la crítica de los mencionados y opuestos dogmatismos y la bibliografía correspondiente, remito a mis ensayos: "Valutazioni morali e giuridiche nella crisi dell' etica individuale", en Studi senesi, 1950, v. LXII, págs. 178-241; “Aspetti della critica dei valori etico-giuridici nel pensiero contemporaneo", en Riv. int. fil. dir., 1950, págs. $235^{-267}$, y "La interpretazione del non verificabile" en Il saggiatore, 1954, págs. 6g-88.)

$6 \mathrm{~K}$. Mannheim, Ideology and Utopia, al cuidado de L. Wirth, New York, 1953, págs. 235-236; al cuidado de A. Santucci, Bolonia, 1957, págs. 265-266. Hay trad. esp. México, 1941, F.C.E.

7 Cfr. G. Husserl, Recht und Zeit, Francfort del Meno, 1955, págs. 10 y siguientes. 
2. La interpretación de los fines no puede no implicar el conocimiento de los medios idóneos para su realización y, a la inversa, el conocimiento de los medios no puede no implicar la interpretàción de los fines; se trata de dos procedimientos que no se identifican, que no se confünden en uno, pcro que no pueden pensarse como separados.

El conocimiento de los medios no puede usurpar el lugar de la interpretación de los fines. La elección de un fin fundamental podrá ser más o menos "razonable". Una de las tareas prácticas de la reflexión crítica y filosófica es hacer que las elecciones de finalidades resulten tan "razonables" como sea posible en el ámbito de las situaciones concretas en que tales elecciones se producen. Al decir "tan razonables como sea posible" no se alude a lo "racional" en sentido estrictamente científico-analítico, matemático o empírico. "Racional" es aquello que es verificable como verdadero (o como falso) de acuerdo con métodos de control y de verificación adoptados por quien se propone realizar una investigación científica. En este sentido, dentro del plano de la racionalidad científica, estricta y rigurosamente entendida, entre lo verdadero y lo falso no existe una diferencia de más o de menos, sino la que separa al sí del no.

El anulamiento de sla esfera de lo "razonable", 8 que es la regla de la cultura, en la' esfera de lo racional, es el resultado de una mística fe en los podéres mágicos de la ciencia," hoy un tanto difusa. "Una parte de la humanidad cree ciegamente que, dado que la ciencia nos revela el mecanismo observable de la naturaleza, un estudio más profundo de aquél nos llevará a adquirir plena conciencia de todo lo que el hombre anhela saber." Contra esta fe mística reaccionan en nuestros días los mismos hombres de ciencia. ${ }^{10}$

"Nuestra ciencia - dice un físico contemporáneo de gran autoridad-, es un instrumento que se adapta a las tareas para las que ha sido construido", 11 "pero no a todos los objetivos" ni, por tanto, a todas las finalidades últimas que caracterizan. el ambiente histórico y cultural en que la misma ciencia desenvuelve su actuación. "El mundo que nos circunda es un mundo infinito para la experiencia y la especulación; una gota de agua, un granito de arena nos plantean problemas que podrian interesar, durante

s Sobre la distinción de "racional" y "razonable", "le premier".. "concernant ce qu'il y a de contraignant; de démonstratif, le deuxième, concernant ce qu'il y a d'argumentatif. et de non contraignant dans la raisonn", ver, entre los trabajos de Ch. Perelman, la relación presentada recientemiente, en la sesión del 23 de abril de 1960 , a la Sociedad Francésa de Filosofía: "L'idéal de rationalité et la règle de justice" (en el Bulletin de la Societé française de Philosophie, $196 \hat{1}$, n. 1 , págs, 1-5, y especialmente $1 \mathrm{a}$ pág. 8 ), así como lä importante discusión subsecuente (ib., págs. 15-5o).

9. Asi, E. N. C. Andrade, An approachi to Modern Physics, 'Londres, 1956 , en la traducción de M. Montagnana, Introduzione alla fisica moderna; Turín, 1958, pág. 379 .

10 Loc, cit.

11 Lac, cit. 
toda la vida, a la mente más desarrollada. Lo que descubrimos y tenemos por muy importante se halla determinado por nuestra elección." 12

La ciencia es un instrumento adecuado a las tareas para las que ha sido construida; el funcionamiento de tal instrumento implica la elección de estas tareas. Por eso el mismo autor a quien aquí me refiero puede justamente decir que la elección de las tareas es, por sí misma, "arbitraria"; arbitraria, se entiende, desde el punto de vista de la racionalidad científica. De hecho la elección de las tareas no es racional en el sentido de que no es el resultado de una actividad científicamente controlable, sino su presupuesto. No es racional, pero esto no significa que histórica y"culturalmente no deba ser razonable.

Las tareas y las finalidades de la ciencia son elegidas por el científico entre las finalidades' y las posibilidades que le ofrece cada vez la situación cultural en que el trabajo de la ciencia es desplegado. Como interpretación de situaciones culturales, la filosofía cumple, ni más ni menos, una función esclarecedora de las posibilidades culturales y de las más o menos razonables finalidades que constituyen el campo de elección de la ciencia. Cuáles son las condiciones de posibilidad de esta función esclarecedora y crítica de la filosofia, cómo puede llevarse a término, cuáles son sus mejores procedimientos, todas éstas, y otras que podrían hacerse, son preguntas que atañen, por decirlo así, al problema interno de la filosofía. (Pero, naturalmente, ha-ı blar de tal problema no debe significar hipostasiarlo, esto es, planteárselo al margen de las concretas y particulares exigencias históricas y humanas que lo determinan, ni desconectarlo de los problemas particulares de la religión, la cultura, el arte, la ciencia, etc., con los cuales tiene concreta e indisoluble conexión en las diversas ocasiones en que surge.) Ahora bien: en el campo de los conocimientos y de las técnicas sociales y jurídicas, donde las finalidades de los comportamientos humanos, los intereses fundamentales y predominantes y los llamados valores asumen prima facie un carácter determinante, diverso y mayor aún en lo que respecta a las ciencias físicas y naturales, la susodicha función interpretativa y esclarecedora de la filosofía, en sus aspectos social $y$ jurídico, adquiere un relieve particular y gran importancia. De hecho, en los razonamientos jurídicos se hallan siempre directamente implicadas las situaciones culturales de los juristas (legisladores, intérpretes, administradores, jueces, teóricos del derecho) y las de los destinatarios de esos razonamientos.

El significado de cualquier concepto jurídico, considerado dentro del contexto de las nociones a que pertenece, no puede dejar de hallarse siempre condicionado por las finalidades prácticas de quien lo propone. ${ }^{13}$ Estas fina-

12 Op. cit., págs. $357-358$.

13 Ver una importante discusión en A. C. Jemolo, "Ancora sui concetti giuridici" en Rivista del diritto commerciale, 1955, PI, págs. 130-160, y autores allí citados. 
lidades prácticas no son concebibles como simples finalidades absolutamente particulares y arbitrarias, precisamente en cuanto se hallan, cada vez, ligadas al contexto, implícito o explícito, de finalidades, de intereses y de valores a que pertenecen; $y$, por ende, surgen cada vez de una realidad cultural concreta caracterizada por un horizonte móvil que circunscribe las finalidades últimas. Misión de la filosofía del derecho es precisamente esclarecer las finalidades últimas a que se hallan ligados los presupuestos de la actividad cognoscitiva, interpretativa y técnica del jurista.

El actual contraste de las visiones del mundo y, consiguientemente, de las situaciones culturales y de las finalidades últimas que se superponen unas a otras en el espacio y en el tiempo, explica, en parte al menos, la importancia preeminente que en ciertos ambientes es hoy atribuida, incluso por juristas técnicos, a la filosofía jurídica, precisamente en cuanto filosofía y actividad distinta de la teoría general del derecho.

3. Toda actividad jurídica tiende, tanto más cuanto en mayor grado quiera ser científica, a ser sistemática y a presentarse como teoría general del derecho. La teoría general dél derecho ha sido entendida, sin más, como sisteria de los conceptos juridicos fundamentales. ${ }^{14}$ En mi opinión, teoría general del derecho es también, en cierto sentido, la implícita tendencia presente e inmanente en toda actividad jurídica particular que quiera ser científica y rigurosa. Toda ciencia jurídica particular tiende a ser teoría general del derecho a través de la determinación de los significados de uso, más o menos constantes, de los conceptos comunes a esa ciencia y a otras ciencias juridicas particulares. Una teoría general del derecho es, en suma, una sistematización de los conceptos fundamentales empleados en varias ciencias jurídicas particulares. Esta sistematización se realiza determinando las relaciones constantes entre los significados de uso de los diversos conceptos.

A menudo, la modificación del significado de un concepto rompe la unidad y coherencia sistemática de un conjunto de conceptos jurídicos, por lo que esa modificación impone la necesidad de modificar otros conceptos, a fin de establecer la coherencia sistemática destruida por aquélla. Los ejemplos que en tal respecto podrian ponerse son numerosísimos. La crítica y la revisión del concepto de derecho subjetivo por obra de Duguit, verbigracia, ha llevado a este autor en forma necesaria a transformar o modificar una serie de otros conceptos jurídicos fundamentales. ${ }^{15}$ La reelaboración del concepto de autonomía, hecha en Italia por Santi Romano, ha

14 Así por ejemplo, H. Nawiaski, Allgemeine Rechtslehre als System der rechtlichen Grundbegriffe, Zurich, 1948 .

15 Remito a mi ensayo "Il metodo di L. Duguit", en Studi senesi, 1951, v. LXIII, fasc. I, págs. 1-39, y a las obras y autores allí citados. Ver, además, la obra más reciente de G. Telles Junior, A Criação do Direito, São Paulo, 1953, v. II, págs. 339 y siguientes y, entre las diversas comunicaciones conmemorativas del centenario del nacimiento de Duguit, la de M. J. Brethe De La Gressaye, "L'influence des idées du Doyen Duguit sur le droit privé", en Revue juridique et économiqué du Sud-Ouest, Série juridique, 1959, págś. 205-220. 
ejercido, dentro del ámbito del pensamiento de este autor, una influencia modificadora sobre otros conceptos y figuras jurídicas fundamentales. ${ }^{16}$

Pero la unidad sistemática de toda teoría general del derecho, si bien se determina a través de relaciones de interdependencia entre varios conceptos y figuras jurídicas de carácter fundamental, a veces resulta asimismo condicionada por el paradigma, el modelo y la definición general de la juridicidad que cada teoría general del derecho asume, implica y presupone en sí misma. En toda teoría general del derecho se halla necesariamente implicada una definición general del derecho cuyo significado no es indiferente, sino que tiene conexión con los significados de los diversos conceptos juridicos fundamentales y sus relaciones. Así, por ejemplo, si se considera técnicamente útil una concepción normativa del negocio jurídico, y se habla de normas necesariamente creadas por las voluntades de los contratantes o por la del prometiente, no se puede aceptar en forma coherente cierta concepción general de la norma jurídica como voluntad y como mandato. ${ }^{17}$

La concepción general del fenómeno.jurídico en términos normativos, la de la función de la norma ya como sollen, ya como sein, o la general del fenómeno jurídico como voluntad de quien políticamente manda o como voluntad general de los coasociados, la acentuación del conflicto de los intereses o de su resolución como momento central de la experiencia jurídica, la inicial concepción del fenómeno jurídico en los términos de la llamada separación positivista entre derecho y moral o, viceversa, en los términos de una concepción del derecho como mínimo. ético, entiéndase esta expresión como se entienda; la visión de la jerarquía de las fuentes del derecho basada sobre la concepción estatista de éste -sobre la concepción monista del orden jurídico combinada coherentemente con la "philosophie du contrat social" y sobre el llamado "monisme de la loi"- o, viceversa, la concepción general del derecho como orden y como institución y, por tanto, como pluralidad de ordenamientos: estas y otras posibles asunciones y presupuestas representaciones del fenómeno jurídico no pueden dejar de incidir sobre los significados de los diversos conceptos fundamentales elaborados dentro del ámbito de la teoría general del derecho y sobre sus relaciones sistemáticas. Ahora bien, evidentemente se trata de asunciones iniciales y de presupuestas representaciones que no son puramente arbitrarias ni puramente convencionales, sino que constituyen, a su vez, el resultado de elecciones implícitas y explícitas entre las finalidades fundamentales y las posibilidades que forman el horizonte que circunscribe los ambientes culturales en que respectivamente se manifiesta cualquier teorización general del derecho. ${ }^{18}$

16 Ver, por ej., de Santi Romano, Frammenti di un dizionario giuridico, Milán, 1947.

17 Cf. mi artículo "Norma negoziale e paradigma normativo" en Rivista trimesirale di diritto e procedura citile, 1959, págs. $1219^{-1234 .}$

18 Cf. E. García Máynez, La Definición del Derecho. Ensayo de perspectivismo juridico, Xalapa, 1960 (2a ed. revisada), págs. 128 y siguientes. 
En la raíz de las elecciones metodológicas del jurista está el ambiente en que tales elecciones ocurren: sea que el jurista exprese con estas elecciones las finalidades del ambiente cultural en que vive, sea que pretenda modificar de cualquier modo tales finalidades; su actitud no puede ser nunca exclusivamente descriptiva. No se trata, para él, solamente de describir hechos, sino, ante todo, de valorizar ciertas finalidades respecto de las cuales aquéllos adquieren significado.

4. Según la opinión de un notable analista contemporáneo del lenguaje jurídico, G. L. Williams, ${ }^{19}$ en una norma jurídica hay siempre dos elementos: uno valorativo, constituido por el deseo de - y la tendencia a- influir sobre los comportamientos en el sentido expreso de la norma, y otro referencial (referential), o indicación de la situación o de la conducta que el precepto tiende a realizar. Sólo de este segundo elemento es posible un conocimiento que se refiera a hechos, sea verdaderamente científico $y$, por tanto; verificable como verdadero o falso. Por ejemplo, el precepto "no robarảs" podrá ser visto como juicio de hecho (o fáctico) probablemente falso, esto es, como falsa afirmación de que la gente no roba. Pero en la medida en que sea obedecido, el juicio fáctico por él exprèsado podrá declararse verdadero. ${ }^{20}$

Sobre la base de esta distinción entre el elemento valorativo, que no puede ser objeto de ciencia, en cuanto no verificable como verdadero (o como falso), y el fáctico, susceptible de verificación o de ciencia, ${ }^{21}$ Williams cree poder someter a la ciencia el precepto jurídico o establecer la posibilidad de una ciencia de las normas juridicas, pero en su discurso aparece, a mi entendêr, una dificultad insuperable. Si realmente la norma, en cuanto jurídica; imprescindiblemente consta de dos elementos: valorativo y referencial, un conocimiento, o ciencia, entendido en sentido específico, que sólo se refiera a uno de los elementos, el referencial, no es ya conocimiento de normas. En general, y para prescindir de la postura particular de Williams, si se admite que el fenómeno juridico es una unidad de hecho y de valor, o si se cree que lá ciencia juridica, en cuanto conocimiento verificable, sóbo puede ser conocimiento de hechos, no es posible admitir un conocimiento científico del derecho. No es posible tout court un conocimiento juridico; desde el punto de vista de la ciencia ${ }^{-}$el derecho es un hecho: Sólo es posible una sociología empírica que ni siquiera podrá ostentar la etiqueta de jurídica. ${ }^{22}$

19 G. L: Williams, "Language and the Law", publicado por entregas en The Law Quar. terly Review, 1945 (págs. 71-86, 179-195, 293-903, 384-406) y $194^{6}$ (págs. $3^{87-406) . ~}$

20 Op. cit., págs. $405-406$.

21 Loc. cit.

22 Ver, en sentido análogo, una crítica a la posición de A. Ross, en el importante libro de F. Castberg, Próblems of Legal Philosophy (segunda edición revisada), Oslo, 1957, págs. 4-5. Cfr. A. Ross, On Law and Justice, Londres, 1958, por ejemplo el parágrafo sobre "The Mutual Interaction between Belief and Attitude", en las-págs. 300-305. 
Por un lado la visión de la norma jurídica como un complejo de valor y de hecho; por otro lado una concepción del conocimiento jurídico según el modelo de las ciencias naturales, hacen imposible el conocimiento del derecho. Toda distinción abstracta entre elemento fáctico y elemento valorativo y cultural del derecho - y la reducción de los conceptos jurídicos a proposiciones descriptivas - pueden conducir à posiciones acríticamente realistas y esencialísticas y, dicho de otro modo, hacer creer que los conceptos de la ciencia jurídica son, por sí mismos, verdaderos (o falsos), en cuanto corresponden a una presunta realidad esencial y universal a la que deben ser referidos; pueden también contribuir a que se dé carácter absoluto a los significados de esos conceptos y a concebirlos como si fueran, ellos mismos, universales y constantes, independientemente de sus matrices culturales y de las condiciones históricas y ambientales de su uso. La reducción del concepto jurídico a juicio de hecho puede hacer creer al jurista en la naturaleza universal y constante de ciertas relaciones de hechos que sean necesariamente expresables a través de determinados conceptos fundamentales formalmente inmutables.

Una actitud metodológica que pretenda ser puramente empirista es, en suma, susceptible de trastrocarse fácilmente en una postura metafísica acrítica, esencialista y realista. Es decir, al querer reducirlo todo a los términos de una presunta investigación empíricamente verificable, de la que queden fuera las elecciones ideológicas, valorativas y culturales, se corre el riesgo de absolutizar el objeto de la propia investigación y de creer, por ejemplo, que cierto concepto, postulado como fundamental, es el único posible o constituye la más adecuada e importante expresión de cierta realidad, cuando, en vez de ello, no es sino expresión de determinada elección cultural, históricamente condicionada. Bajo este aspecto me parecen perfectamente aceptables algunas recientes revisiones críticas de categorías jurídicas tradicionales, cuya utilidad técnica es puesta en crisis por la complcjidad misma de la vida social y jurídica contemporánea. Piénsese en la reciente literatura crítica sobre la noción de derecho subjetivo. Contra la tradición pandectística que ha atribuido "y en gran medida sigue atribuyendo al valor de algo absoluto" a la noción del derecho subjetivo, "elevándola al rango de categoría universal e imprescindible de toda construcción jurídica", ${ }^{23}$ se insiste sobre .los "jaques técnicos" 24 sufridos por tal noción y se considera, por ejemplo, la teóría del abuso del derecho como "extravagante" correctivo, inventado para obviar los inconvenientes prácticos inherentes al uso de la

23 Cfr. R. Orestano, "Diritti soggettivi e diritti senza soggetto. Linee di una vicenda concettuale", en Jus, 1960, págs. 149-196, articulo al que remito también por la bibliografía. Me refiero aquí a la pág. 189 .

24 M. Villey, "Abrégé du droit naturel classique" en Archives de Philosophie du Droit, N. 6,1961 , extracto, pág. 69 . 
misma; ${ }^{25}$ además, se destacan justamente los elementos históricos, culturales e ideológicos que han determinado, al menos en parte, sea la formación de tal concepto, sea la atribución, al mismo, de un significado absoluto e históricamente incondicionado. 26

5. En la literatura jurídica de carácter metodológico se encuentran a menudo mezcladas, en un mismo autor, dos presuposiciones antitéticas. Por un lado se proclama la necesidad, para el jurista, de atenerse a los hechos y a su naturaleza positiva, prescindiendo de cualquier valoración de los mismos para evitar una opinión arbitraria o la falsificación de éstos. Por otro lado, se reconoce que los que interesan al jurista no escapan a las valoraciones culturales, consuetudinarias y de orden moral, por lo que, si se prescinde de cualquier valoración de los mismos, su significado se nos escapa. ${ }^{27}$

En realidad, esta segunda presuposición destruye a la primera. La referencia a la naturaleza pura del hecho, tal como se -manifiesta en las más toscas y'menos cautas formulaciones, debe ceder a la comprobación de la naturaleza cultural y valoradora del hecho que interesa al jurista;28 y ello precisamente porque, fuera de cualquier proceso de valoración, el hecho permanece desprovisto de significado. ${ }^{20}$ La referencia a un hecho, sea cual fuere la forma en que se le considere, es referencia a su significado; pero tal significado implica la relación del hecho con otros hechos y, por tanto, en cada caso, un punto de vista desde el cual esas relaciones adquieren importancia: el punto de vista de un observador, conexo con su posición de observador, su situación cultural y ambiental, su manera de valorar, su capacidad de ponerse en el sitio de otros observadores $y$ de participar en las valora. ciones ajenas. Las premisas valorativas del jurista no. pueden, bajo este aspecto, dejar, de influir sobre sus hipótesis metodológicas.

- Por otra parte, no es creíble que las hipótesis metodológicas y las técnicas del jurista sean, cada vez, analíticamente derivables; por medio de relaciones y razonamientos deductivos, de sus premisas valorativas. Entre éstas-y los resultados particulares del trabajo del jurista (las decisiones prác. ticas a que tiende, etc.) no existe una simple conexión formal deductiva de lo general a lo particular.30 - Las finalidades últimas, culturales y ambien-

25 Loc. cit. .

26 Orestano, op. cit., pág. 193.

27 Por ejemplo, estos dos temas están presentes, según creo, en el pensamiento de F. S. Cohen, en Ethical Systems and Legal Ideals. An Essay on the Foundations of Legal Criticism, Ithaca, Nueva York, 1959 (1 ed. 1933). Cfr., por ejemplo, pág. 14 y siguientes y pág. 286 y siguientes.

128 Cfr. J. Paul, The Legal Realism of Jerome' N. Frank. A Study of Fact-Skepticism and the Judicial Process, La-Haya, 1959, pág. 143 y siguientes.

29 Cfr. P. Sayre, An Introduction to a Philosoplyy of Law, Iowa, 1951, pág. 1 y siguientes.

30 Como quizás todavía lo creía T. Ascarelli a través de su, aún así, viva y moderna perspectiva (Cfr. Saggi di diritto commerciale, Milán, 1955, pág: 2 y siguientes, pág. 485 y siguientes). 
tales, los varios paradigmas generales del derecho y, por tanto, las premisas valorativas del jurista, no son equiparables a las de silogismos cuyas conclusiones estuvieran constituidas por los resultados particulares del trabajo del mismo jurista. $^{31}$ Las premisas valorativas no son premisas silogisticas ni de un procedimiento formal de deducción analítica. Son simplemente los imprescindibles elementos que determinan los límites de ese campo de posibilidades dentro del cual, cada vez, el jurista escoge y formula, implícita o explícitamente, sus hipótesis metodológicas, para la realización de las finalidades teóricas y prácticas que tiene a la vista al iniciar sus investigaciones.

En el sentido ya dicho, también las premisas sistemáticas de la teoría general son, por consiguiente, a fin de cuentas, premisas culturales, y la renovación de la teoría general a través de la de sus premisas no es exclusivamente reducible a las relaciones de premisas y consecuencias en que pueden configurarse los resultados de la teoría general. La crítica -y la renovación crítica- de las premisas implica aquí un trabajo de esclarecimiento de la’s posibilidades culturales que se ofrecen al jurista técnico y al teórico general, que es propiamente la tarea de la filosofía del derecho o, también, del jurista técnico, que en cierto sentido se hace filósofo al plantearse el problema crítico de las condiciones de posibilidad de sus presupuestos metodológicos. Incluso las llamadas elecciones de métodos (por las que, en mi sentir, se puede fácilmente demostrar que, en ciertos casos, a un mismo conflicto de intereses pueden dársele soluciones opuestas según las diversas premisas metodológicas de que se parte para resolverlo) y también las elecciones del método en el sentido, por ejemplo, de la llamada jurisprudencia de intereses o de la jurisprudencia de conceptos, son a menudo reducibles a elecciones de presupuestos culturales $y$, consiguientemente, de finalidades últimas. ${ }^{32}$

Por otra parte, las diversas tentativas encaminadas a situar la teoría general del derecho en una esfera de objetividad científica pura, indiferente a la mutabilidad de las condiciones culturales, sociales e históricas; la implícita o explícita negación del nexo entre ciencia pura del derecho y cultura $y$, por tanto, entre ciencia jurídica y filosofía; la apariencia de una ciencia "pura" del derecho independiente y autónoma en lo que respecta a finalidades, valores, ideologías, etc; todos estos ensayos de realización de la perfecta autonomía de la ciencia jurídica, inspirados en el modelo de las ciencias naturales, son, en sí mismos, como se podría demostrar fácilmente con ejemplos concretos, consecuencia de la elección o elecciones de determinados presupuestos culturales e ideológicos.33 Las mismas condiciones de

31 Cfr. I. Tammelo "Law, Justice and Social Reality", en Osterr. Zeitschrift für öffentliches Recht, 1957, pág. 347 y siguientes.

32 Para ejemplos y bibliografía remito a mi artículo "La scelta del metodo nella giurisprudenza" en Rivista Trimestrale di diritto e procedura civile, 1957, págs. 1054-1060.

33 Ver el reciente ensayo de C. Cossio, "La gnoseología del error", en La Ley, Buenos Aires, 24 dic. 1960, pág. 4 . 
posibilidad de una "ciencia jurídica pura" y las exigencias a que se quiere dar satisfacción al proponer que la filosofía jurídica. sea sustituida por una teoría general del derecho, son hoy condiciones y exigencias que únicamente pueden ser valoradas y comprendidas a fondo en la medida en que se les relacione con las finalidades y los intereses culturales que las determinan (esto es, precisamente, en cuanto se les considere y plantee como cuestiones filosófico-jurídicas).

También la concepción de la teoría general del derecho como "nomographische Normwissenschaft", como "Rechtsnormologie", como "Rechtsnormenlehre", distinta de la "Rechtsgesellschaftslehre", y de la "Rechtsideenlehre", 34 puede sólo tener significado en relación con las finalidades prácticas y teóricas que pretenden realizar los que proponen tal distinción en el ambiente cultural de que forman parte. Pero ciertamente no se trata de una distinción referida a dos momentos -o partes - separados de una presunta realidad en sí del fenómeno jurídico, que se hallase ante el jurista observador como algo universal $\mathrm{e}$ inmutable.

En conclusión, en cuanto pesquisa dirigida -a esclarecer los presupuestos de la ciencia y de la técnica jurídicas, la filosofía del derecho es una actividad empeñada en recorrer y volver a recorrer el terreno roturadó por aquéllas; y ello precisamente è virtud de la implicación concreta de cultura y técnica a que me he referido, si bien esquemáticamente y de modo muy general, al principio de estas notas. Indudablemente, al plantearse continuamente como problema los presupuestos de la ciencia y de la técnica jurídicas, tal como se presentan, no abstractamente considerados en sí mismos, sino dentro de los contextos científicos y técnicos a que pertenecen, la filosofía del derecho puede desplegar ya una función de conservación, ya una función de dirección y renovámiento. Conservàción dé valores y de fines todavía culturalmente válidos contra eventuales, ilusorias, efímeras, demasiado precipitadas o poco críticas negaciones. Renovación ${ }^{35}$ y dirección en lo que respecta al señalamiento y determinación de fines y valores nuevos, que emergen de la mudable realidad concreta de la historia.

\section{Luigi Bagolini}

(Trad. de Eduardo Garcia Máynez.)

Universidad de Génova

34 Nawiaski, op. cit., págs. 2-3.

35 Por lo demás,- como dice 0 . Brusiin ("Legal Theory. Some considerations" en Archiv für Rechts- und Sozialphilosophie, 1957, pág. 408), "a criticism of the behaviour and traditional thinking of jurists may meet. with strong resistance and not further the popularity of legal theory. It appears rather as a disturbing-factor. But a legal theory that is not disturbing would lack practical value"." 